\title{
Testing 5 virtual methods to teach field Geology online with suggested future modifications
}

\author{
DANIEL DAVID GREGORY, SOFIA L PANASIUK, HEIDI \\ E TOMES AND A JULIA ANDERSEN
}

University of Toronto

Presenting Author: daniel.gregory@utoronto.ca

In 2020 Covid-19 necessitated cancelation of in-person classes prompting us to develop an online introductory geology field course to allow students to complete their degree requirements. Few online field courses had been designed previously so the best method of delivery was unclear. To test effective online teaching methods, we developed 5 different methodical approaches. First, we designed an online VR room where 3-D rendered outcrops showing a range of specific geologic features simulated a field-like environment. Students could visualize these structures, discuss with one another and practice making field notebook entries. Next, we developed 3-D printed blockmodels of folded strata that were mailed to the students with compasses so they could learn to take structural measurements as they would in the field. These measurements were used to construct a geologic cross-section using the kink method. Third, a mapping area was built using Google Earth, where the students used a collection of supporting photographs, aerial photographs, and videos from different stations to construct a geologic map. This was supplemented with structural measurements and rock samples mailed to the students. This exercise taught the students how to construct a geologic map, meeting a major field course learning objective. The last two activities were designed to teach skills which tend to be more accessible in the online format in comparison to a more traditional field setting, due to difficulties in getting access to diamond drill core or active mining sites. The first of these introduced diamond drill core logging, an important skill in exploration geology, but often overlooked in traditional field courses. The activity provided students with a combination of high-resolution core photos and hyper-spectral mineralogical data provided by Corescan and available from the Minnesota Geological Survey. Second, we taught detailed mapping skills used trench, bench of underground mapping in mining/mineral exploration. This mineral exploration skill uses the Anaconda Method of mapping and taught the students important steps and information needed to construct these detailed maps. In this contribution we outline the results of our course, evaluate the effectiveness of each approach, and lastly propose ways to improve its efficacy. 